\title{
Análise temporal e quantificação da expansão urbana em função do crescimento do agronegócio no município de Conceição das Alagoas/MG
}

\author{
Roberson Borges Rodrigues ${ }^{1}$, Daniel Pena Pereira ${ }^{1 *}$, Pompeu Paes Guimarães ${ }^{2}$, Davi de Carvalho Fiedler ${ }^{3}$
}

RESUMO: O crescimento da urbanização foi um fenômeno potencializado no século passado devido a grandes mudanças socioeconômicas na população brasileira. Objetivou-se utilizar os dados disponíveis pelo Projeto MapBiomas na quantificação do crescimento urbano do município de Conceição das Alagoas dentre 1986 e 2018 comparando com fontes de satélites abertos. Foram utilizadas duas fontes de dados rasters: a primeira, o raster classificado pelo Projeto MapBiomas v4.1; e a segunda, a utilização de satélites abertos na identificação e delimitação do munícipio (a delimitação foi feita de forma manual utilizando como imagem guia dados dos sensores Landsat 5 TM (Órbita 221e Ponto 074) e Sentinel 2B - Quadro T22KGD e Órbita 36). Após concluído o trabalho, encontrou-se que a cidade expandiu cerca de $177 \%$ nessas três décadas, o que representa um valor bastante considerável a ser considerado no plano diretor dos próximos anos do munícipio. Observou-se ainda que, nas imagens do Projeto Mapbiomas de 1986, houve uma possível interferência causada pela ausência de pavimentação asfáltica em suas ruas, o que pode de fato provocar uma interpretação equivocada nos parâmetros de reflectância das classes. De forma geral, notou-se que o setor sucroenergético influenciou expressivamente essas mudanças na expansão da infraestrutura urbana da cidade e que isso pode ocasionar, por sua vez, causar problemas e consequências ambientais comuns entre os municípios, destacando-se as questões relacionadas ao uso e à ocupação da terra, à mobilidade urbana e ao saneamento ambiental).

Palavras-chave: Sensoriamento remoto, Planejamento de cidades, Infraestrutura, Setor sucroenergético

\section{Temporal analysis and quantification of urban expansion as a function of agribusiness growth in the municipality of Conceição das Alagoas/MG, Brazil}

\begin{abstract}
The growth of urbanization has been a potentialized phenomenon in the last century due to major socioeconomic changes in the Brazilian population. The objective of this study was to use the data available by the MapBiomas Project in the quantification of urban growth in the municipality of Conceição das Alagoas between 1986 and 2018 compared to open satellite sources. Two sources of rasters data were used: the first, the raster classified by the MapBiomas Project v4.1; and the second, the use of open satellites in the identification and delimitation of the municipality (the delimitation was done manually using data from the Landsat 5 TM sensors (Orbit 221e Point 074) and Sentinel 2B - Frame T22KGD and Orbit 36). After completing the work, it was found that the city expanded about $177 \%$ in these three decades, which represents a very considerable amount to be considered in the master plan for the next years of the municipality. It was also observed that, in the images of the 1986 Mapbiomas Project, there was a possible interference caused by the absence of asphalt pavement in its streets, which may in fact cause a misinterpretation in the reflectance parameters of the classes. In general, it was noted that the sugar-energy sector significantly influenced these changes in the expansion of the city's urban infrastructure and that this can, in turn, cause environmental problems and common consequences among municipalities, highlighting issues related to the land use and occupation, urban mobility and environmental sanitation.
\end{abstract}

Keywords: Remote Sensing, Cities' planning, Infrastructure, Sugar-energy sector

\section{INTRODUÇÃO}

De acordo com a Lei Provincial n 2464 de 21 de setembro de 1878, Conceição das Alagoas recebe o título de distrito do município de Uberaba e permaneceu nesta condição até a data de 17 de dezembro de 1938, quando pelo decreto-lei estadual $\mathrm{n}^{\circ} 148$, foi elevado a categoria de município e deixou de ser considerado um distrito da cidade de Uberaba (MINAS GERAIS, 1938). Tendo nesta data como principal fonte de economia o garimpo de pedras preciosas, substituído adiante pela indústria de fabricação de cerâmica e tijolos. E isso permaneceu como principal fonte econômica até meados das décadas de 1980, período em que se iniciou a Revolução Verde no país (SANTOS, 1986).

Embora uma parcela considerável dos habitantes naturais do munícipio opte pela migração à munícipios maiores como Uberaba, cidade vizinha, observa-se que ocorreu uma migração de pessoas de estados da região nordeste para o local. Esse fato foi ocasionado pela exigência de mão de obra para trabalho em usinas sucroenergéticas localizadas próximas ao município. Portanto, evidencia-se que esse marco histórico e diversificação da população local ocorreu em massa dentre os anos de 1997 e

\footnotetext{
Recebido em 17/04/2020; Aceito para publicação em 28/07/2020

${ }^{1}$ Instituto Federal do Triângulo Mineiro

2 Universidade Federal Rural do semi-Árido

${ }^{3}$ Escola Superior de Agricultura Luiz de Queiroz

*E-mail: danielpena@iftm.edu.br
} 
2007, datas destacadas na mudança da sistematização agrícola no Brasil. Isso foi demonstrado pela preferência que o cultivo de cana de açúcar passou a ter como foco a região Sudeste e Centro-Oeste do país (IBGE, 2007).

Atualmente, a economia local é fortemente baseada no cultivo de cana de açúcar, grãos e por último a fabricação de cerâmica, visto que está fora um dia considerada uma forte fonte de renda (PREFEITURA DE CONCEIÇÃO DAS ALAGOAS, 2020). Devido a isto, nota-se que nas décadas seguintes o município de Conceição das Alagoas sofrera um aumento populacional considerável, tendo em vista que de acordo com o censo demográfico de 1980 a cidade possuía uma população de 13.552 habitante contra 22.955 habitantes, segundo dados do censo do ano de 2010 (IBGE, 2010). A análise da expansão territorial da malha urbana da cidade pode auxiliar a tomada de decisões na administração geral do município.

$\mathrm{O}$ uso de técnicas de sensoriamento remoto, juntamente com Sistemas de Informações Geográficas possibilitam de uma forma viável e eficaz, a identificação e validação das mudanças causadas pelo homem no uso e ocupação da superfície terrestre (FLORENZANO, 2002). Utilizando o método de identificação do uso do solo de forma manual, tendo como base uma imagem remota dos anos de estudo, é possível realizar o método de álgebra de mapas a fim de obter a diferença das duas geometrias que representam a infraestrutura do munícipio.

O Projeto MapBiomas tem por objetivo realizar essa identificação de forma automatizada, utilizando métodos de classificação por meio do uso de aprendizado de máquinas por floresta aleatória (Randon Forest) obtendo-se uma acurácia média de $82,4 \%$ em todo o território de estudo (MAPBIOMAS, 2020).

Assim, o proposto trabalho tem por objetivo utilizar os dados disponíveis pelo Projeto MapBiomas na quantificação do crescimento urbano do município de Conceição das Alagoas dentre 1986 e 2018.

\section{MATERIAIS E MÉTODOS}

\section{Caracterização do município estudado}

O município de Conceição das Alagoas, situado a Oeste do estado de Minas Gerais, localizado na região conhecida como Triângulo Mineiro possui uma população de 22.955 habitantes de acordo com o Censo Demográfico realizado pelo Instituto Brasileiro de Geografia e Estatística (IBGE, 2010). Sua economia é baseada na agropecuária, com o foco no cultivo da cana de açúcar e grãos, mantendo assim a fidelização aos municípios confrontantes no quesito fontes de economia local (PREFEITURA DE CONCEIÇÃO DAS ALAGOAS, 2020).

Um fator determinante para o crescimento da cidade nas últimas décadas, foi a instalação de duas usinas sucroenergéticas que fornecem empregos a milhares de pessoas. É importante ressaltar que as características geográficas do munícipio são favoráveis a agricultura, pois o relevo encontrado é predominantemente plano e possui um índice pluviométrico anual de aproximadamente $1589 \mathrm{~mm}$ (PREFEITURA DE CONCEIÇÃO DAS ALAGOAS, 2020).

\section{Coleta dos dados e processos metodológicos}

O Projeto MapBiomas coleção 4.1 é iniciativa promovida por uma rede colaborativa de especialistas em uso da terra, ocupação e biomas, disponibilizada na plataforma do Google Earth Engine (https://code.earthengine.google.com/). Com esses dados é possível a análise de um arquivo de imagem com inúmeras classes de uso e ocupação do solo de qualquer município do Brasil a partir do ano de 1986.

Sabendo-se da acurácia da classificação do Projeto MapBiomas de 82,4\%, realizou-se um comparativo com a delimitação feita de forma manual, como forma de apoio na delimitação da infraestrutura urbana do município, utilizando como imagens guia dados dos sensores Landsat 5 TM do ano de comparação (Órbita 221e Ponto 074) e Sentinel 2B (Quadro T22KGD e Órbita 36).

Portanto, o proposto trabalho fez-se o uso de duas fontes de dados rasters. A primeira $o$ raster classificado pelo Projeto MapBiomas v4.1 e a segunda a utilização de satélites abertos na identificação e delimitação do munícipio em anos mais antigos. Como o caso do ano de 1986, onde, embora já havia infraestrutura urbana, a ausência de pavimentação asfáltica pode ter ocasionado uma classificação equivocada pelo Projeto MapBiomas v4.1.

Após a aquisição dos dados para o trabalho dos dois anos alvos, 1986 e 2018, foram iniciados os processos de delimitação das áreas urbanas com técnicas de geoprocessamento e comparação por diferença simétrica. Esses processos constituíram-se na observação da classe de valor 24 (área urbana) da imagem obtida pelo Projeto MapBiomas v4.1 e comparação com uma imagem de cor natural da mesma época para certificação de uma delimitação fidedigna. Posteriormente, foram realizados os cálculos de áreas em hectares (ha) das duas delimitações e feito um comparativo no software QGIS v3.4 Madeira finalizando a análise e a geração de mapas. A Figura 1 ilustra todo o processo realizado em forma de um fluxograma. 


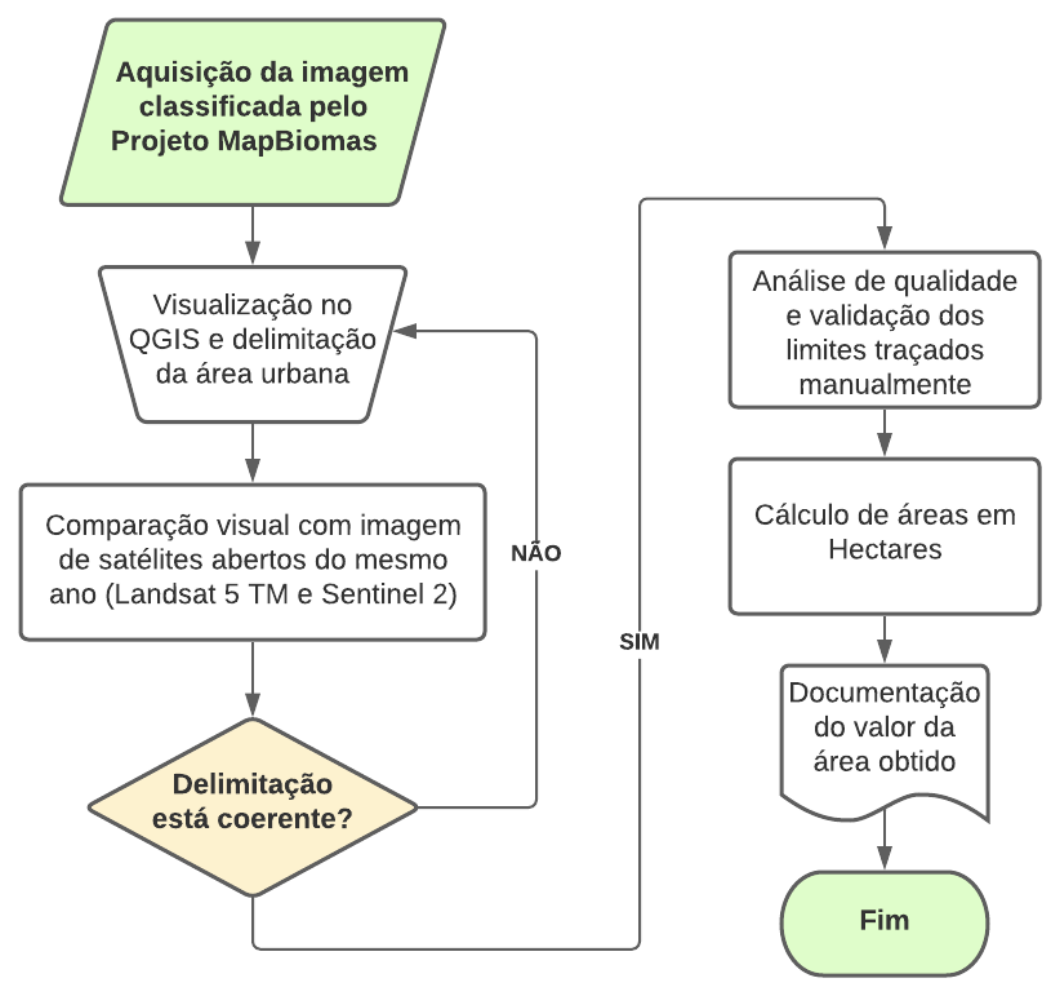

Figura 1- Fluxograma dos processos realizados na delimitação da área urbana da cidade de Conceição das Alagoas/MG nos anos de 1986 e 2018.

\section{RESULTADOS E DISCUSSÃO}

Em posse do banco de dados para o trabalho, foram iniciados os processos no QGIS v3.4 Madeira de acordo com o diagrama ilustrado anteriormente na Figura 1. Desse modo, buscou-se inicialmente realizar a delimitação baseando-se no arquivo extraído pelo Projeto MapBiomas e posteriormente realizar uma comparação visual e correção baseado em imagens em cor natural de um sensor disponível na época. Como resultado do ano de 1986 realizou-se a delimitação da infraestrutura urbana baseando-se no Projeto MapBiomas (Figura 2).

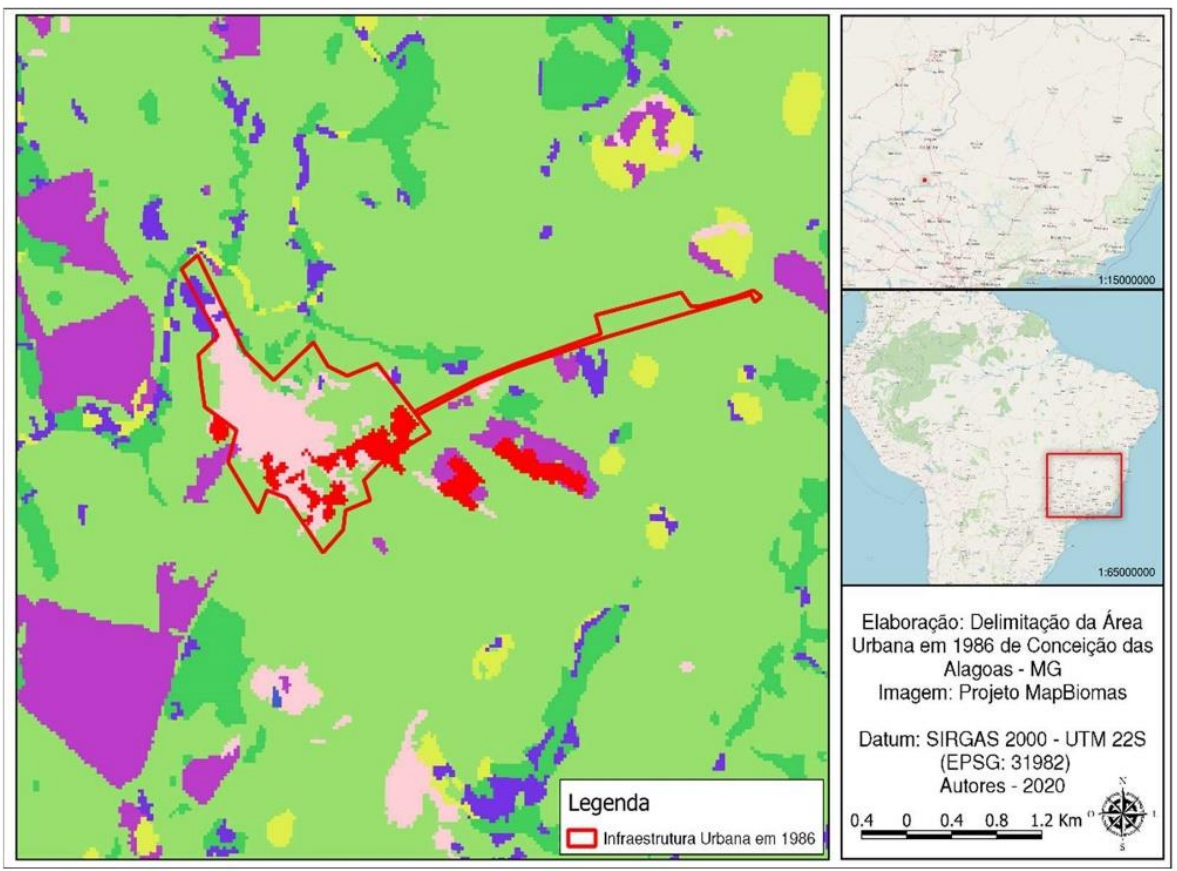

Figura 2 - Mapa de localização elaborado no QGIS 3.4 Madeira contendo ao fundo a imagem adquirida no Projeto MapBiomas v4.1 de 1986. 
Neste primeiro caso, originou-se uma área de 232,74 hectares no que diz infraestrutura urbana. À essa época, nota-se uma cidade com potencial de crescimento tendo em vista a vasta economia da região voltada às atividades silvo pastoris e ao auge da Revolução Verde (SANTOS, 1986). Nota-se que ocorrem divergências dos resultados entre a classificação entregue pelo Projeto MapBiomas e a análise de uma imagem em cor natural da mesma época, sendo que neste caso fora utilizado a imagem do sensor Landsat 5 TM. Embora o Projeto MapBiomas mostre uma parcela da área identificada como realmente área urbana, nota-se que houve muita interferência do cenário em sua classificação. Acredita-se que essa interferência seja causada pela ausência de pavimentação asfáltica em suas ruas, o que pode de fato provocar uma interpretação equivocada nos parâmetros de reflectância das classes.

Em contrapartida, o ano de 2018, tendo uma delimitação baseada na mesma fonte de dados do Projeto MapBiomas, resultou em uma delimitação mais fidedigna a comparação com sensores remotos. Neste segundo caso, originou-se uma área de 644,89 hectares referente a infraestrutura urbana. Conjuntamente com este levantamento, realizou-se comparativo da expansão urbana do munícipio, onde é possível notar, de forma espacial, o modo em que ocorreu essa expansão (Figura 3).
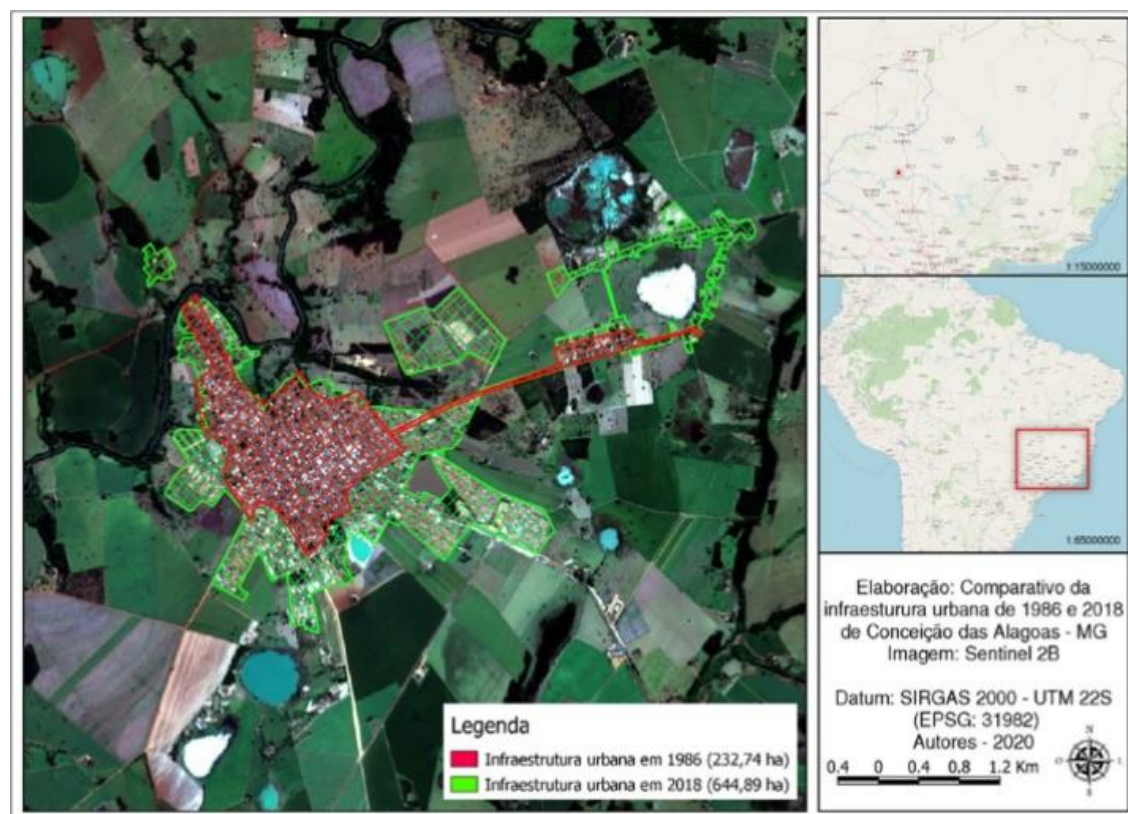

Figura 3- Comparativo elaborado no QGIS 3.4 Madeira contendo ao fundo a imagem adquirida pelo sensor Sentinel 2B datada em 2018.

Nota: Em destaque na cor vermelha encontra-se a delimitação da área urbana em 1986 e em verde os limites no ano de 2018.

Em comparação com sensores remotos, foi utilizado o sensor Sentinel 2B em sua composição natural. O sensor passivo Sentinel 2B é mantido pelo Programa Copernicus, uma iniciativa da Agência Espacial Europeia (ESA) e é responsável pela sistemática obtenção de imagens da terra e águas costeiras desde 2015 com resoluções espaciais que podem alcançar até 10 metros. Observa-se no Anexo I, o resultado da delimitação da área urbana do ano de 2018 contendo ao fundo a imagem extraída pelo Projeto Mapbiomas; em seguida, o Anexo II remete à mesma delimitação, porém ao fundo uma imagem do Satélite Sentinel 2B em sua composição natural.

Observa-se que houve um crescimento dentre esses anos de aproximadamente $177 \%$. O avanço da área urbana se dá ao desenvolvimento econômico da região, as atividades de agricultura se potencializaram no cultivo da cana de açúcar, visto que, em um raio de $25 \mathrm{~km}$ se têm duas usinas sucroenergéticas que demandam o cultivo dessa obra prima para produção de açúcar, etanol e energia elétrica renovável. Esse intenso processo de urbanização pode acarretar impactos representativos para o meio urbano do município, como por exemplo, um aumento em inundações, decorrente do aumento de áreas impermeabilizadas, assim como o escoamento superficial. O comparativo das áreas obtidas é observado na Tabela 1 
Tabela 1. Conceição das Alagoas (MG): Comparativo da área urbana do município nos anos de 1986 e 2018.

\begin{tabular}{cccc}
\hline Ano & Área (ha) & Área $\left(\mathrm{Km}^{2}\right)$ & $\%$ \\
\hline 1986 & 232,74 & 2,33 & 1,00 \\
2018 & 644,89 & 6,45 & 2,77 \\
\hline Comparativo & $+412,15$ & $+4,12$ & $+177 \%$
\end{tabular}

A expansão urbana é de se esperar em todo estudo temporal em cidades. Como no caso de Andrade, Sousa e Gomes (2019), em que ao investigarem o Eixo da Rodovia Presidente Dutra observaram forte influência deste no crescimento da área urbanizada dos municípios ao seu redor. E isso corrobora com as afirmações de Villaça (2001) sobre o papel das vias regionais para a integração territorial e na atuação como catalisadoras do processo de urbanização.

Souza e Frutuoso (2018), analisando o crescimento urbano do estado do Rio de Janeiro entre os anos 1980-2010, a expansão da malha urbana é destacada pelo aumento das taxas de crescimento da população e do número de municípios. No período de 1980-1991, a população urbana fluminense cresceu a um ritmo de $1,45 \%$ ao ano, enquanto a população rural reduziu-se a um ritmo médio anual de 3,87\%, tendo o crescimento global se dado a um ritmo de $1,5 \%$ ao ano. Para o período de 2000-2010, os ritmos de crescimento das populações urbanas, rurais e totais fluminenses foram, respectivamente, $1,28 \%$ a.a., 0,91\% a.a., e 1,20 a.a. E o número de municípios saltou de 64 em 1980 para 92 em 2010.

Stanganini e Lollo (2018) relataram problemas relacionados aos impactos ambientais do processo de urbanização e, principalmente, à supressão da vegetação nativa. $E$ que essas mudanças na composição das cidades brasileiras apontam para um conjunto de problemas e consequências ambientais comuns entre os municípios, destacando-se as questões relacionadas ao uso e à ocupação da terra, à mobilidade urbana e ao saneamento ambiental. Em seu estudo no município de São Carlos/SP entre os anos de 1980 e 2015 perceberam um crescimento da área urbanizada saltando de $36,45 \mathrm{~km}^{2}$ para 102,70 $\mathrm{km}^{2}$, um aumento de mais de $280 \%$. Finalizada a quantificação das áreas, passa-se a observar na Figura 4, detalhamento das regiões que se originaram da expansão urbana desde 1986.

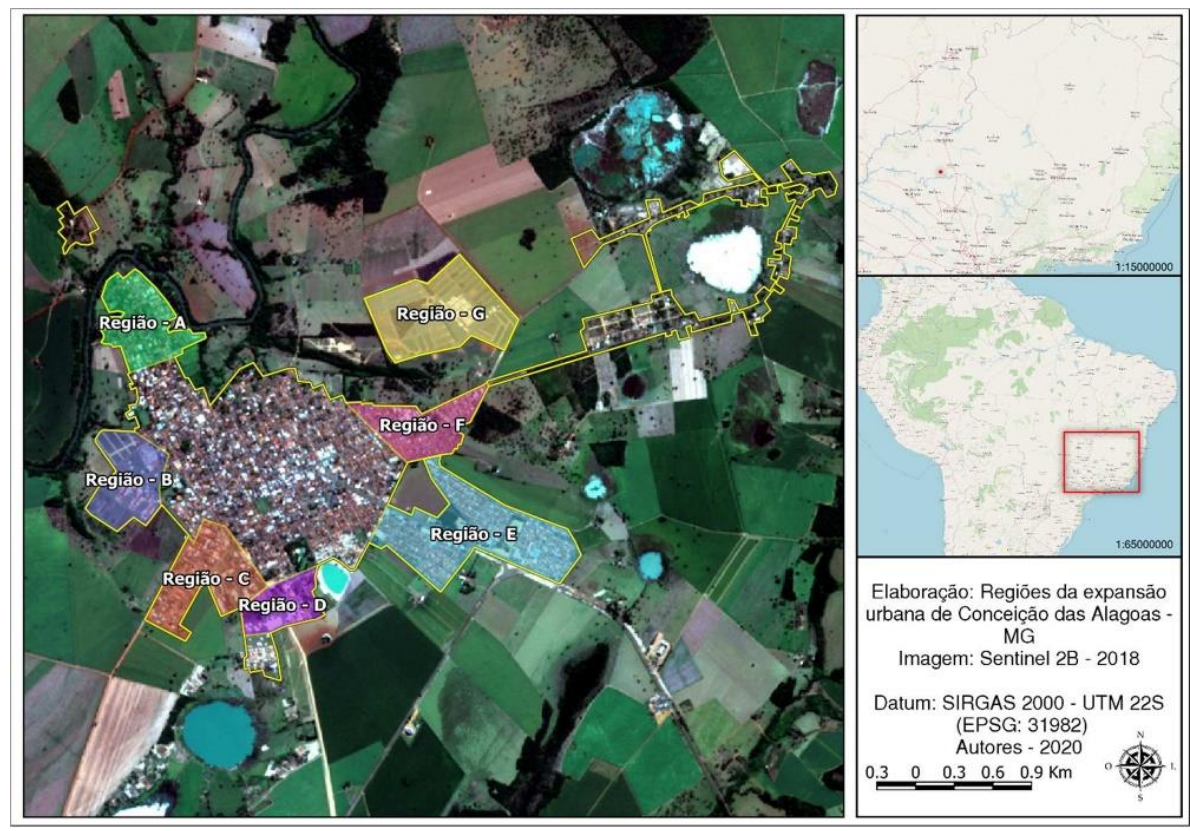

Figura 4 - Mapa com observações elaborado no QGIS 3.4 Madeira contendo ao fundo a imagem adquirida pelo sensor Sentinel 2B datada em 2018.

Pelo exposto, o crescimento expressivo de $177 \%$ de área urbana entre 1986 e 2018 em Conceição das Alagoas/MG, teve marcado sua evolução em função do grande avanço da economia na região, fortemente baseada no setor sucroenergético da cana de açúcar. A Figura 4 destaca pontos classificados como regiões onde determinou-se se citar algumas características do local expandido. As regiões foram delimitadas de acordo com a expansão urbana identificada através da diferença simétrica das duas delimitações de 1986 e 2018. Posteriormente, as regiões expandidas foram subdivididas em sub-regiões (A à $\mathrm{G}$ ) de modo a citar aspectos socioeconômicos identificados no local que retratam a forma com que essa expansão se sucedeu. 
Região A: é caracterizada por uma região onde as famílias relativamente conservadoras optaram por construírem os seus lares, fato este que é evidenciado pela presença da Igreja Matriz localizada nessa região.

Região B: essa região está em grande expansão no momento tendo em vista que possui lotes de terrenos e muitas casas em construção. Nota-se que atualmente é uma região propensa a investimentos devido a sua localização central e se tratar de um bairro categorizado de pessoas com média renda.

Região C: nesse local é visível que as construções são mais elaboradas, fato este ocorreu devido a essa região estar ao lado de um bairro considerado de classe média/alta pela população da cidade. Neste local está sendo construída uma escola e se encontra próximo as principais escolas e centros comerciais da cidade.

Região D: local confrontante à recém construída Lagoa Park, foi revitalizada uma lagoa da região e criado um espaço para práticas de exercícios físicos e lazer. Essas duas últimas regiões são consideradas de famílias de média/alta renda.

Região E: essa região teve grande expansão na construção de casas voltadas às famílias com um menor poder aquisitivo, inclusive pode-se observar que essa região, principalmente mais a sua esquerda, teve grande crescimento após as famílias que vieram para agregar mão de obra as empresas da região passarem a se instalar definitivamente no munícipio. A sua direita, está em expansão a construção de casas do programa Minha Casa Minha Vida do Governo Federal.

Região F: neste local encontra-se a região mais humilde dos locais citados. Aqui, habitam em sua grande maioria famílias de baixa renda.

Região G: embora seja considerada distante do centro da cidade, atualmente é ligada pela principal avenida e possui um potencial médio de expansão devido estar sendo finalizada a obra de pavimentação da Rodovia que dará acesso à Rodovia Federal BR-262. Atualmente no local é facilmente encontrado lotes a venda e casas em construção. Acredita-se que essa região possa ter tido um regresso na expansão devido a criação da Região $\mathrm{B}$, sendo está mais próxima ao centro e possuindo terrenos com valores próximos ao vendido neste local. Fato este, ocasiona a queda dos valores desses bairros e faz com que se transformem em investimentos não tão vantajosos.

O setor do agronegócio influenciou positivamente essas mudanças. Segundo Araújo e Araújo Sobrinho (2018), o desenvolvimento dos municípios na região do Triângulo Mineiro/Alto Paranaíba se deu conjuntamente com a expansão do setor sucroenergético. De certa forma, isso impactou, nos municípios aonde a atividade se implantou, as relações e o mercado de trabalho, os fluxos migratórios, a articulação da região, as redes de produção global, bem como questões ambientais decorrentes da produção em larga escala.

\section{CONCLUSÕES}

Conclui-se que o proposto trabalho foi de suma importância na mensuração da expansão urbana ocorrida dentro os anos de 1986 e 2018. Neste contexto, evidenciou-se a ocorrência de um crescimento de aproximadamente $177 \%$ neste período. Foram analisadas imagens de duas fontes de dados diferentes e demonstrado que embora o Projeto MapBiomas possua uma excelente proposta na quantificação e qualificação do uso e ocupação da terra, são necessárias algumas observações e principalmente uma validação manual antes de se tomar decisões ou quantificar valores importantes.

Observa-se que foi de suma importância a validação em segundo nível, onde fora delimitado manualmente a infraestrutura urbana e possibilitada uma visualização mais detalhada do local. Diante disso, nota-se que a imagem mais atual do Projeto MapBiomas possui uma maior fidedignidade a delimitação realizada manualmente baseada na imagem em cor natural do Sentinel 2B, fato este pode estar ligado à evolução dos sensores remotos disponíveis hoje e a própria formação física da cidade, onde passara a ter massa asfáltica que auxilia na identificação por reflectância solar.

Além disso, foram discutidas ocorrências que influenciaram na expansão e classificadas as zonas do município embasadas na classificação socioeconômicas do local. Fato tal, mostrou-se que a tese de que grande parte da expansão ocorrida se deu pelo fortalecimento da economia microrregional e a expansão do cultivo de cana de açúcar na região, necessitando assim, de mão de obra para trabalho.

\section{REFERENCIAS}

ANDRADE, D. J.; SOUZA, A. A. M.; GOMES, C. Análise temporal da expansão urbana nos municípios do Vale do Paraíba Paulista. Mercator (Fortaleza), 18. 2019.

ARAÚJO, D. F. C.; ARAÚJO SOBRINHO, F. L. A dinâmica do setor sucroenergético no Triângulo Mineiro/Alto Paranaíba. Revista Cerrados, v. 18, n. 01, p. 248-277. 2020.

MINAS GERAIS. Decreto-lei $\mathbf{n}^{\mathbf{0}} \mathbf{1 4 8}$ de 17 de dezembro de 1938. Fixa a divisão territorial do Estado de Minas Gerais. Belo Horizonte, MG, 1938. Disponível em: https://www.almg.gov.br/consulte/legislacao/completa/co mpleta-nova-

min.html?tipo=DEL\&num=148\&ano=1938\#: :text=DEC RETO\%2DLEI\%20148\%20de\%2017,1943\%2C\%20e\%2 0d\%C3\%A1\%20outras\%20provid\%C3\%AAncias.

Acesso em: 01 jun. 2020. 
IBGE, Instituto Brasileiro de Geografia e Estatística. Resultados divulgados no Diário Oficial da União. Censo do ano de 2010. Rio de Janeiro, 2010. Disponível em: https://censo2010.ibge.gov.br/resultados.html. Acesso em: 05 jun. 2020.

IBGE, Instituto Brasileiro de Geografia e Estatística. Levantamento sistemático da produção agrícola: prognóstico da produção agrícola. Rio de Janeiro, 2007. Disponível me: https://www.ibge.gov.br/estatisticas/economicas/agricultu ra-e-pecuaria/9201-levantamento-sistematico-daproducao-agricola.html?=\&t=publicacoes. Acesso em: 06 jun. 2020.

FLORENZANO, T. G. Imagens de satélite para estudos ambientais. 97 p. São Paulo: Oficina de Textos, 2002. Disponível

em: https://www.bdpa.cnptia.embrapa.br/consulta/busca?b=ad $\&$ id $=14985 \&$ biblioteca $=$ CPATSA\&busca $=$ autoria: $\% 22 \mathrm{G}$. $\% 22 \& q$ Facets $=$ autoria: $\% 22 \mathrm{G} . \% 22 \&$ sort $=\&$ paginacao $=\mathrm{t} \&$ paginaAtual=49.Acesso em: 06 jun. 2020.
PREFEITURA DE CONCEICAO DAS ALAGOAS. Dados Gerais do município. Disponível em: http://www.conceicaodasalagoas.mg.gov.br. Acesso em: 01 jun. 2020.

SANTOS, J. S. M.; LAPOLLI, E. M. Comparação Tabular da Expansão Urbana Dos Municípios de Itapema, Porto Belo e Bombinhas em Santa Catarina, Brasil, no Período de 1985 a 2002. Universidade Federal de Santa Catarina, 2003. Disponível em: http://www.bvsde.paho.org/bvsAIDIS/PuertoRico29/mafr a.pdf. Acesso em: 07 jun. 2020.

SOUZA, J.; FRUTUOZO, J. V. P. Rio de Janeiro: considerações sobre os processos de expansão urbana e interiorização do crescimento (1980-2010). urbe, Revista Brasileira de Gestão Urbana, v. 10, n. 1, p. 124-139. 2018.

STANGANINI, F. N.; LOLLO, J. A. O crescimento da área urbana da cidade de São Carlos/SP entre os anos de 2010 e 2015: o avanço da degradação ambiental. urbe, Revista Brasileira de Gestão Urbana, v. 10, n. 1, p. 118128, 2018 . http://dx.doi.org/10.1590/21753369.010.supl1.ao14 